Ambiente \& Água - An Interdisciplinary Journal of Applied Science
ISSN 1980-993X - doi:10.4136/1980-993X
www.ambi-agua.net
E-mail: ambi-agua@agro.unitau.br

\title{
Sorção de elementos traços em solos de áreas de disposição final de resíduos sólidos urbanos
}

\author{
doi: 10.4136/ambi-agua.1274
}

Received: 09 Jan. 2014; Accepted: 27 May 2014

\section{Luiz Fernando Coutinho de Oliveira*; Jéssica Soares Freitas; Camila Marques Generoso; Ronaldo Fia}

\author{
Universidade Federal de Lavras (UFLA), Lavras, MG, Brasil \\ *Autor correspondente: e-mail: coutinho@deg.ufla.br, \\ jessica_soares_freit@engambiental.ufla.br, \\ cmg@engambiental.ufla.br, ronaldofia@deg.ufla.br
}

\section{RESUMO}

A disposição inadequada dos resíduos sólidos urbanos no solo compromete a qualidade do solo, da água e do ar e constitui fonte de compostos orgânicos, solventes e elementos traços. Neste trabalho foi estudado a sorção dos elementos $\mathrm{Cd}, \mathrm{Cu}, \mathrm{Li}, \mathrm{Pb}$ e $\mathrm{Zn}$ nos solos das áreas de disposição de resíduos sólidos urbanos dos municípios de Campo Belo, Lavras e Pouso Alegre, MG com a finalidade de se verificar a vulnerabilidade da contaminação das águas subterrâneas. As isotermas de sorção apresentaram um bom ajuste ao modelo de Freundlich, permitindo a sua utilização na previsão de retenção destes elementos traços nos solos de áreas de disposição final de resíduos sólidos urbanos dos municípios em questão para as concentrações estudadas. O solo do município de Pouso Alegre foi o que apresentou a menor potencialidade de lixiviação dos elementos traços avaliados, sendo o solo de Lavras o de maior vulnerabilidade no que se refere ao potencial de contaminação das águas subterrâneas, exigindo um maior controle na disposição de resíduos sólidos contendo elementos traços facilmente solubilizados.

Palavras-chave: isoterma de sorção, lixiviação, contaminação da água.

\section{Sorption of trace elements in soils of final disposal of municipal solid waste}

\begin{abstract}
Improper disposal of municipal solid waste in soil impacts the quality of soil, water and air and is a source of organic compounds, solvents and trace elements. In this work, we studied the sorption of the $\mathrm{Cd}, \mathrm{Cu}, \mathrm{Li}, \mathrm{Pb}$ and $\mathrm{Zn}$ in soils at solid waste disposal areas in the municipalities of Campo Belo, Lavras and Pouso Alegre, MG. The sorption isotherms showed a good fit to the Freundlich model, allowing us to predict the retention of these trace elements in soils from final disposal of municipal solid waste in the municipalities in the studied concentrations. The Pouso Alegre soil had the lowest potential for the leaching of trace elements; alternatively, the Lavras soil was the most vulnerable to the risk of groundwater
\end{abstract}


contamination, requiring greater care with regard to the disposal of solid waste containing trace elements that are easily soluble.

Keywords: sorption isotherm, leaching, water contamination.

\section{INTRODUÇÃO}

Segundo Martins et al. (2011) o termo elemento traço tem sido utilizado para definir elementos químicos que em baixas concentrações no ambiente podem vir a constituir uma fonte potencial para a poluição ambiental. Os elementos traços podem ser encontrados no solo em solução, adsorvidos aos sítios de troca, incorporados à superfície da fase inorgânica, como óxidos de $\mathrm{Al}, \mathrm{Fe}$ e de $\mathrm{Mn}$, participando de reações de precipitação e dissolução e ligados a compostos orgânicos.

Os efeitos gerados pela disposição dos resíduos sólidos repercutem, principalmente, na contaminação das águas e do solo. Esses resíduos acabam sendo constituídos de uma mistura muito complexa e de natureza diversa, cujos principais constituintes são: material orgânico, papel, vidro, plástico, elementos metálicos e tecnológicos, sendo esses últimos, fontes dos principais elementos traços liberados para o meio ambiente (Aniceto e Horbe, 2012; Gouveia e Prado, 2010; Celere et al., 2007).

Como produto da biodegradação gerado pela passagem da água através do maciço dos aterramentos dos resíduos sólidos em processo de decomposição, tem-se o líquido percolado chamado de chorume. Esse líquido possui elevada carga de poluentes orgânicos e inorgânicos e, ao entrar em contato com o solo, pode modificar, de forma intensa, suas características físicas, químicas e biológicas, bem como as das águas subterrâneas, caso consiga alcançá-las (Oliveira e Jucá, 2004).

De acordo com Piaz e Ferreira (2011) e Kemerich et al. (2013), o descarte indevido de resíduos contendo os metais pesados como as pilhas, baterias, tintas, dentre outros, apresentam elementos químicos altamente poluentes tanto ao homem quanto à natureza, podendo ser lixiviados e contaminar o solo, o lençol freático e também a fauna e a flora das regiões circunscritas. Dentre esses elementos com elevada toxicidade destacam-se a $\mathrm{Ag}, \mathrm{Cd}$, $\mathrm{Cu}, \mathrm{Hg}, \mathrm{Li}, \mathrm{Mn}, \mathrm{Ni}$ e Pb. Segundo Oliveira e Pasqual (2004), Machado et al. (2011) e Oliveira et al. (2013), dentre os elementos mais presentes no percolado das áreas de disposição de resíduos sólidos urbanos, destacam-se o $\mathrm{Cd}, \mathrm{Cu}$, Li e o Zn .

Embora o solo seja uma barreira natural de proteção aos aquíferos subterrâneos, os fatores que governam sua capacidade em reter elementos traços são extremamente complexos, o que dificulta sobremaneira o seu entendimento e as possibilidades de previsões acerca do comportamento desses elementos, principalmente em longo prazo (Oliveira e Mattiazzo, 2001).

O efeito poluente dos elementos traços no ambiente depende, principalmente, da capacidade dos colóides do solo em sorvê-los e mantê-los retido com alta energia (Pierangeli et al., 2007). Segundo Chaves e Tit (2011) e Oliveira et al. (2010a), a contaminação do solo por elementos traços é extremamente perniciosa por serem altamente persistentes no ambiente. Os elementos traços não podem ser degradados ou prontamente destoxificados pelos seres vivos tornando, ao contrário da maioria dos contaminantes orgânicos, um agravante problema de poluição, ao longo do tempo (Oliveira et al., 2010b).

No processo da sorção, o soluto adere às superfícies das partículas do solo, especialmente argilo-minerais e matéria orgânica, devido a forças de atração decorrentes de cargas desequilibradas nas superfícies dessas partículas, resultantes de imperfeições ou substituições iônicas na estrutura cristalina dos minerais (substituição isomorfa) ou de quebra de ligações nas estruturas moleculares, especialmente nas extremidades (Freeze e Cherry, 1979). A sorção iônica ao complexo de troca do solo faz com que os íons mantenham intercâmbio com a 
solução do solo, proporcionando ora sua retenção junto à fração sólida, ora sua disponibilização no meio aquoso (Tagliaferro et al., 2011).

A sorção pode ser vista como um processo chave para a determinação do destino dos poluentes no sistema solo-água. Esta habilidade que o solo possui na retenção de solutos retarda o seu transporte no perfil do solo. Características e propriedades como teor de argila e de matéria orgânica, capacidade de troca catiônica (CTC), pH entre outras, tem sido avaliadas como possíveis indicadores da capacidade de sorção dos solutos pelo solo (Nicochelli et al., 2012; Corrêa et al., 2011). O pH do solo pode interferir na adsorção de cátions metálicos por meio de mecanismos de adsorção específica e não específica ou eletrostática (Alleoni et al., 2005).

O Conselho Nacional do Meio Ambiente, em suas resoluções no 357 e 420, regulamenta o estabelecimento de critérios e valores orientadores referentes à presença de substâncias químicas, para a proteção da qualidade do solo e da água (Brasil, 2005 e 2009). A resolução n³57 estabelece para as diferentes classes de água (doce, salobra e salina as concentrações máximas dos contaminantes)s. Para o solo e águas subterrâneas a resolução nº 420 estabelece os valores de prevenção e investigação para os contaminantes orgânicos e inorgânicos e recomenda que os valores de referência sejam estabelecidos pelos estados. Alguns grupos de pesquisa do Brasil direcionaram suas pesquisas à obtenção de teores naturais de metais nos solos, objetivando auxiliar na construção de valores orientadores para suas regiões dentre os quais podem se destacar: Oliveira et al. (1998), Fadigas et al. (2002, 2006a e 2006b), Casarini et al. (2002), Campos et al. (2003), Oliveira e Pasqual (2004), Guilherme et al. (2005), Pierangeli et al. (2009), Caires (2009), Biondi et al. (2011), Paye et al. (2010) e Carvalho et al. (2013).

Em vista do exposto, objetivou-se com este trabalho a análise da sorção do $\mathrm{Cd}, \mathrm{Cu}, \mathrm{Li}$, $\mathrm{Pb}$ e $\mathrm{Zn}$ em solos de três formas distintas de disposição de resíduos urbanos gerados pelas cidades de Campo Belo, Lavras e Pouso Alegre, MG, com finalidade de identificar a potencialidade de contaminação do solo e das águas subterrâneas em função dos resultados obtidos nos ensaios de sorção.

\section{MATERIAIS E MÉTODOS}

Para a realização deste trabalho, foram coletadas amostras deformadas de solo em três áreas de disposição final de resíduos sólidos urbanos (RSU) dos municípios de Campo Belo, Lavras e Pouso Alegre, sob jurisdição da Superintendência Regional de Meio Ambiente e Desenvolvimento Sustentável (Supram) do Sul de Minas Gerais. Em Campo Belo, os resíduos sólidos urbanos são dispostos em um aterro sanitário municipal localizado nas coordenadas geográficas de $20^{\circ} 51^{\prime} 47^{\prime}$ ' S e $45^{\circ} 17^{\prime} 46^{\prime}$ ' W; em Lavras, em um vazadouro a céu aberto lixão ( $21^{\circ} 16^{\prime} 23^{\prime}$ ' S e $\left.44^{\circ} 55^{\prime} 34^{\prime \prime} \mathrm{W}\right)$ e em Pouso Alegre $\left(22^{\circ} 15^{\prime} 33^{\prime \prime} \mathrm{S}\right.$ e $\left.46^{\circ} \mathrm{W}\right)$ em um lixão, o qual foi encerrado a quatro anos. Segundo a estimativa do IBGE (2013) a população dos municípios de Pouso Alegre, Lavras e Campo Belo foi respectivamente de 140.223, 99.172 e 53.656 habitantes, e a geração diária de resíduos desses municípios, conforme Franco (2012), foi de 77,7; 54,4 e 29,7 $\mathrm{t} \mathrm{dia}^{-1}$, respectivamente.

Para cada local de amostragem, foram colhidas amostras compostas de aproximadamente $2 \mathrm{~kg}$ de solo, coletadas com auxílio de trado holandês na profundidade de 0 a $60 \mathrm{~cm}$, abaixo da superfície das plataformas de disposição de resíduos sólidos urbanos. Inicialmente, as amostras de solo foram destorroadas e peneiradas com malha de 2,0 $\mathrm{mm}$ de abertura e, posteriormente, secas em estufa a $105^{\circ} \mathrm{C}$ para obtenção da TFSE (Terra Fina Seca em Estufa) por um período de $48 \mathrm{~h}$ conforme Paye et al. (2010). Após secagem, as amostras foram armazenadas em sacos de polietileno e parte foi encaminhada ao Departamento de Ciência do Solo da Universidade Federal de Lavras (UFLA) para a caracterização química e física, 
segundo as metodologias preconizadas pela Embrapa (1997). Não foram determinadas as concentrações do $\mathrm{Cd}, \mathrm{Cu}, \mathrm{Li}, \mathrm{Pb}$ e $\mathrm{Zn}$ presentes nos solos estudados, uma vez que o estudo objetivou analisar a sorção do aporte desses elementos provenientes da disposição dos resíduos sólidos urbanos no solo.

O potencial de sorção e de lixiviação do $\mathrm{Cd}, \mathrm{Cu}, \mathrm{Li}, \mathrm{Pb}$ e $\mathrm{Zn}$ nos solos estudados foram avaliados pela análise dos valores obtidos para o fator de retardamento e coeficiente de distribuição linear da isoterma de Freundlich. O coeficiente de distribuição linear e o fator de retardamento foram estimados por meio da análise das isotermas de sorção, curvas obtidas a partir de ensaios de equilíbrio em lote que, por sua vez, consistem na agitação de misturas compostas por uma porção de solo e uma solução contendo um contaminante com concentração inicial conhecida. A agitação mantém as partículas sólidas em suspensão, disponibilizando toda sua superfície ao contato com a solução durante o tempo necessário para que ocorram as reações químicas de interação solo-contaminante. Em seguida, foi feita a separação das fases sólida e líquida e determinou-se a concentração de equilíbrio da solução, sendo que pela diferença entre as concentrações inicial e de equilíbrio obteve-se a concentração do contaminante que foi retida pelo solo (Lange et al., 2002 e Souza et al., 2006).

Empregando-se as concentrações do $\mathrm{Cd}, \mathrm{Cu}, \mathrm{Li}, \mathrm{Pb}$ e $\mathrm{Zn}$ em solução e adsorvida ao solo, fez-se então, o ajuste das isotermas de Freundlich nos modelos linear e potencial. Para tal, foram pesadas em balança de precisão 2,0g de TFSE de cada solo analisado, as quais foram transferidas para cubetas de centrífugas e adicionados $10 \mathrm{~mL}$ das soluções de Cloreto de Cádmio, Cloreto de Cobre, Cloreto de Lítio, Cloreto de Chumbo e Cloreto de Zinco nas concentrações de 0,$1 ; 0,2 ; 0,5 ; 1,0 ; 5,0$ e $10,0 \mathrm{mg} \mathrm{L}^{-1}$, preparadas em Cloreto de Cálcio $\left(0,01 \mathrm{~mol} \mathrm{~L}^{-1}\right)$ como eletrólito-suporte segundo recomendação de Chaves et al. (2008). As concentrações utilizadas no estudo da sorção basearam-se nas resoluções CONAMA e nos valores de referência para os elementos estudados, no solo e na água subterrânea, recomendados para os trabalhos citados na introdução. Tomaram-se com base os valores de referência no solo e na água, pois uma vez que o elemento não se encontra adsorvido no complexo de troca do solo, estará disponível em solução para ser lixiviado, podendo atingir os aquíferos proporcionando a contaminação das águas subterrâneas.

As cubetas contendo os solos e as soluções salinas foram acondicionadas em Becker, e posteriormente, colocadas em uma mesa orbital modelo Solab180. Os conjuntos Beckercubetas, contendo os solos e as soluções foram agitadas de maneira contínua por um período de $24 \mathrm{~h}$ em uma agitação constante de $60 \mathrm{rpm}$, permitindo assim um maior contato entre os sítios de troca dos solos com as soluções salinas, conforme metodologia descrita por Abreu et al. (2011). Após o período de agitação na mesa orbital, as cubetas foram transferidas para uma centrífuga angular fixa com capacidade de 12 cubetas modelo Centribio 4000 e por um período de $15 \mathrm{~min}$ em uma rotação constante de $1200 \mathrm{rpm}$, foram centrifugadas com a finalidade de separar a solução sobrenadante. As soluções sobrenadantes foram acondicionadas em frascos de vidro devidamente limpos com uma solução de ácido nítrico, seguidas de dupla lavagem com água deionizada. Todas as amostras foram acidificadas com ácido nítrico até atingirem um $\mathrm{pH}<2,0$ e assim foram preservadas e mantidas em refrigeração em uma câmara de DBO modelo Solab 200/364 a uma temperatura constante de 2,0oC até o momento da determinação das concentrações $\mathrm{Cd}, \mathrm{Cu}, \mathrm{Li}, \mathrm{Pb}$ e $\mathrm{Zn}$ em solução, seguindo as recomendações da CETESB (2001).

A concentração do Li foi determinada em um espectrofotômetro de chamas modelo Quimis 398M2 e dos demais elementos em um espectrofotômetro de absorção atômica Perkin Elmer Modelo Analyst 800 com forno de grafite, no Laboratório de Geoquímica Ambiental do Departamento de Ciência do Solo da UFLA. As concentrações do $\mathrm{Cd}, \mathrm{Cu}, \mathrm{Li}, \mathrm{Pb}$ e $\mathrm{Zn}$ 
adsorvida nos solos estudados foram obtidas pela diferença entre as concentrações inicial e de equilíbrio das soluções aplicadas e dos sobrenadantes, respectivamente (Equação 1).

$$
\mathrm{S}=\left(\mathrm{C}_{\mathrm{i}}-\mathrm{C}_{\mathrm{f}}\right) \frac{\mathrm{Vol}}{\mathrm{m}}
$$

em que:

$\mathrm{S}=$ concentração dos elementos adsorvidos ao solo $\left(\mathrm{mg} \mathrm{kg}^{-1}\right)$;

$\mathrm{C}_{\mathrm{i}}$ e $\mathrm{C}_{\mathrm{f}}=$ concentração inicial e final do $\mathrm{Cd}, \mathrm{Cu}, \mathrm{Li}, \mathrm{Pb}$ e $\mathrm{Zn}$ em solução (mg L ${ }^{-1}$ );

$\mathrm{m}=$ massa da TFSE $(\mathrm{kg}) \mathrm{e}$

Vol = volume da solução adicionada à cubeta $(\mathrm{L})$.

A isoterma de Freundlich pode ser expressa pelos modelos potencial e linear. O modelo potencial é descrito pela Equação 2.

$$
\mathrm{S}=\mathrm{K}_{\mathrm{f}} \mathrm{C}^{\mathrm{N}}
$$

em que:

$\mathrm{C}=$ concentração do soluto em solução $\left(\mathrm{mg} \mathrm{L}^{-1}\right)$;

$\mathrm{K}_{\mathrm{f}}$ e $\mathrm{N}=$ coeficiente e expoente da isoterma de Freundlich.

Quando o expoente $\mathrm{N}$ for unitário, tem-se uma isoterma linear que corresponde a um caso especial da isoterma de Freundlich (Freeze e Cherry, 1979). Neste caso, segundo Correia et al. (2010) e Arantes et al. (2006), o coeficiente de proporcionalidade da isoterma de Freundlich é chamado de coeficiente de partição (Kd) (Equação 3).

$$
\mathrm{S}=\mathrm{K}_{\mathrm{d}} \mathrm{C}
$$

De posse dos resultados dos ensaios de sorção, fizeram-se os ajustes das isotermas de sorção aos modelos potencial e linear empregando na estimativa dos parâmetros dos modelos o método da minimização da soma dos quadrados dos desvios. Com base no coeficiente angular das isotermas de sorção ajustadas, ou seja, do coeficiente de partição (Kd), fez-se a determinação dos respectivos fatores de retardamento dos elementos traços estudados para os diferentes solos, empregando para tal a Equação 4.

$$
\mathrm{R}=1+\frac{\mathrm{D}_{\mathrm{s}}}{\mathrm{P}} \mathrm{K}_{\mathrm{d}}
$$

em que:

$$
\begin{aligned}
& \mathrm{P}=\text { porosidade total do solo }\left(\mathrm{m}^{3} \text { de poros } \mathrm{m}^{-3} \text { de solo }\right) \text { e } \\
& \mathrm{D}_{\mathrm{s}}=\text { massa específica do solo }\left(\mathrm{kg} \mathrm{m}^{-3}\right) .
\end{aligned}
$$

\section{RESULTADOS E DISCUSSÃO}

A Tabela 1 apresenta o resumo dos resultados das análises física e química dos solos de disposição de RSU dos municípios de Campo Belo, Lavras e Pouso Alegre, MG. Observou-se uma alta porcentagem da fração argila correspondente a $60 \%$ para o solo do município de Pouso Alegre, em comparação ao solo de Campo Belo (43\%) e principalmente ao solo de Lavras que obteve apenas $29 \%$. Sendo assim, o solo de Lavras foi classificado como de 
textura franco argiloso, o de Campo Belo de textura argilosa e o de Pouso Alegre de textura muito argilosa. Embora o solo de Lavras tenha sido classificado como de textura média, foi o que apresentou menor valor médio da condutividade hidráulica do solo saturado, devido à sua menor porosidade o que pode ser confirmada pela sua maior massa específica do solo.

Tabela 1. Análises física e química dos solos de disposição de RSU dos municípios de Campo Belo, Lavras e Pouso Alegre, MG.

\begin{tabular}{|c|c|c|c|c|c|c|c|c|c|c|c|}
\hline Município & Areia & $\begin{array}{l}\text { Argila } \\
\% \\
--\end{array}$ & $\begin{array}{l}\text { Silte } \\
--- \\
\end{array}$ & $\begin{array}{l}\mathbf{D}_{\mathbf{p}} \\
--\mathrm{kg}_{1} \\
\end{array}$ & $\begin{array}{r}\mathbf{D}_{\mathrm{s}} \\
\mathrm{m}^{-3}--\end{array}$ & $\begin{array}{c}\mathbf{K}_{\mathbf{o}} \\
\mathrm{m} \mathrm{d}^{-1}\end{array}$ & $\mathbf{p H}$ & $\begin{array}{r}\text { CO } \\
\text { g kg-1 } \\
\end{array}$ & $\begin{array}{c}\text { CTC } \\
\mathrm{cmol}_{\mathrm{c}} \mathrm{dm}^{-3}\end{array}$ & $\mathbf{K i}$ & $\mathbf{K r}$ \\
\hline Campo Belo & 38 & 43 & 19 & 2660 & 910 & 2,5 & 6,3 & 7,8 & 4,2 & 1,79 & 1,52 \\
\hline Lavras & 30 & 29 & 41 & 2760 & 930 & 0,4 & 5,6 & 1,9 & 2,2 & 1,68 & 1,20 \\
\hline Pouso Alegre & 21 & 60 & 19 & 2710 & 820 & 1,9 & 5,3 & 2,7 & 3,1 & 1,24 & 0,95 \\
\hline
\end{tabular}

Nota: $\mathrm{D}_{\mathrm{p}}=$ massa específica de partículas; $\mathrm{Ds}=$ massa específica do solo; $\mathrm{K}_{\mathrm{o}}=$ condutividade hidráulica do solo saturado; $\mathrm{CO}=$ carbono orgânico; $\mathrm{CTC}=$ capacidade de troca catiônica; $\mathrm{Ki}$ e $\mathrm{Kr}=$ coeficientes de intemperismo.

Pelos valores da CTC apresentados na Tabela 1, os solos avaliados são caracterizados como gibbsíticos/oxídicos $\left(1,61<\mathrm{CTC}<4,3 \mathrm{cmolc} \mathrm{dm}^{-3}\right)$ com baixa capacidade de retenção de cátions, concordando com os valores encontrados para os coeficientes de intemperismo $\mathrm{Ki}<1,8$ e $\mathrm{Kr}>0,75$ (Oliveira et al., 2010b). Dentre os solos classificados como de textura argilosa, o do município de Campo Belo apresentou um maior valor da capacidade de troca catiônica (CTC) em comparação com o solo de Pouso Alegre, o que nos leva a crer que exista diferença no tipo de argilo-mineral presente nesses solos. Pelos valores do coeficiente de intemperismo Kr, podem-se verificar valores mais elevados para o solo de Campo Belo em comparação com o de Pouso Alegre, conferindo uma tendência a ser gibbsíticos e o de Pouso Alegre, oxídico.

O solo de Campo Belo, apesar de apresentar menor quantidade da fração argila em comparação com o de Pouso Alegre, além do tipo de argilo-mineral presente neste solo, verificou-se um $\mathrm{pH}$ mais alto em relação aos demais, propiciando um maior poder de retenção dos elementos traços avaliados (Pierangeli et al., 2007 e Oliveira et al., 2010a). Com relação à quantidade de matéria orgânica nos solos avaliados, apesar de serem baixas, conferiu um aporte de cargas o que pode ser também uma fonte de explicação dos valores de CTC (Tabela 1). Segundo Prata et al. (2000) a sorção está relacionada com a fração mineral do solo, principalmente óxidos de $\mathrm{Fe}$ e $\mathrm{Al}$, tendo a fração orgânica papel secundário, embora Ciotta et al. (2003) verificou que apesar de um pequeno acúmulo de CO no solo, há um reflexo positivo na CTC do solo.

A baixa CTC do solo de Lavras é justificada pela sua baixa quantidade da fração argila com tendência oxídica e pH na faixa ácida. Com o ambiente acidificado, a liberação de H+ propicia uma menor interação de cargas positivas com o solo (Campos, 2010), contribuindo para a redução do poder de retenção do solo de Pouso Alegre e Lavras. Paye et al. (2010) comentam que solos ácidos ( $\mathrm{pH}$ abaixo de 7,0) de modo geral, favorecem a solubilização e mobilização de metais pesados na solução do solo e, por extensão, as perdas desses elementos por lixiviação. Portanto, cuidados redobrados deverão ser tomados com relação à área de disposição de resíduos sólidos do município de Lavras, que opera atualmente como um lixão e apresenta vulnerável no que se refere ao potencial de contaminação das águas subterrâneas.

A Tabela 2 apresenta o ajuste dos parâmetros das isotermas de Freundlich para os modelos linear e potencial, bem como os fatores de retardamento $(\mathrm{R})$ para os elementos $\mathrm{Cd}$, $\mathrm{Cu}, \mathrm{Li}, \mathrm{Pb}$ e $\mathrm{Zn}$. Observou-se que para estes elementos obteve-se um bom ajuste das isotermas com coeficientes de determinação $\left(\mathrm{r}^{2}\right)$ próximos de 1,0 , como se pode observar na Figura 1. 
Com exceção ao Li, não foram verificadas grandes diferenças dos modelos linear e potencial das isotermas de Freundlich, com os expoentes ajustados do modelo potencial próximo de 1,0, que indica uma linearidade das isotermas de sorção para as concentrações dos elementos avaliados neste estudo.

Tabela 2. Parâmetros ajustados das isotermas de Freundlich e fator de retardamento para $\mathrm{Cd}, \mathrm{Cu}, \mathrm{Li}$, $\mathrm{Pb}$ e $\mathrm{Zn}$ e solos de disposição de RSU dos municípios de Campo Belo, Lavras e Pouso Alegre, MG.

\begin{tabular}{|c|c|c|c|c|c|c|}
\hline \multirow{2}{*}{ Elementos } & \multicolumn{6}{|c|}{ Campo Belo } \\
\hline & $\mathbf{K}_{\mathbf{d}}$ & $\mathbf{r}^{2}$ & $\mathbf{K}_{\mathbf{f}}$ & $\mathbf{N}$ & $\mathbf{r}^{2}$ & $\mathbf{R}$ \\
\hline Cd & 8,6955 & $0,9999^{* *}$ & 8,7908 & 0,9979 & $0,9999^{* *}$ & 9,91 \\
\hline $\mathbf{C u}$ & 8,0201 & $0,9999^{* *}$ & 7,8483 & 1,016 & $0,9998^{* *}$ & 9,22 \\
\hline $\mathbf{P b}$ & 6,8445 & $0,9999^{* *}$ & 6,8134 & 1,0037 & $0,9999^{* *}$ & 8,02 \\
\hline Zn & 10,7010 & $0,9999^{* *}$ & 9,9776 & 1,0489 & $0,9999^{* *}$ & 11,97 \\
\hline \multirow[t]{2}{*}{$\mathbf{L i}$} & 6,2503 & $0,8512^{* *}$ & 13,6480 & 0,7032 & $0,9626^{* *}$ & 7,41 \\
\hline & \multicolumn{6}{|c|}{ Lavras } \\
\hline Cd & 7,9932 & $0,9992^{* * *}$ & 7,5789 & 1,0470 & $0,9963^{\text {** }}$ & 10,32 \\
\hline $\mathbf{C u}$ & 7,9858 & $0,9999^{* *}$ & 7,8327 & 1,0123 & $0,9999^{* *}$ & 10,32 \\
\hline $\mathbf{P b}$ & 6,7810 & $0,9999^{* *}$ & 6,8145 & 0,9986 & $0,9999^{* *}$ & 8,91 \\
\hline $\mathbf{Z n}$ & 9,1991 & $0,9935^{* *}$ & 7,5812 & 1,1105 & $0,9923^{* *}$ & 11,73 \\
\hline \multirow[t]{2}{*}{$\mathbf{L i}$} & 5,2446 & $0,8622^{* *}$ & 10,6930 & 0,9477 & $0,9941^{* *}$ & 7,12 \\
\hline & \multicolumn{6}{|c|}{ Pouso Alegre } \\
\hline Cd & 8,8225 & $0,9998^{* *}$ & 8,1191 & 1,0518 & $0,9994^{* *}$ & 11,19 \\
\hline $\mathbf{C u}$ & 8,0204 & $0,9999^{* *}$ & 7,9294 & 1,0087 & $0,9999^{* *}$ & 10,27 \\
\hline $\mathbf{P b}$ & 6,8445 & $0,9999^{* *}$ & 6,5491 & 1,0390 & $0,9975^{\text {** }}$ & 8,91 \\
\hline Zn & 10,5790 & $0,9995^{* *}$ & 9,3865 & 1,0496 & $0,9908^{* *}$ & 13,22 \\
\hline $\mathbf{L i}$ & 6,2315 & $0,8618^{* *}$ & 13,6170 & 0,6966 & $0,9678^{* *}$ & 8,20 \\
\hline
\end{tabular}

Nota: ** significativo em nível de $1 \%$ de probabilidade pelo teste de $\mathrm{t}$.

De um modo geral, observa-se na Tabela 2, que o solo de Lavras apresentou uma menor sorção para todos os elementos avaliados, em função da menor quantidade da fração argila e matéria orgânica, responsável pela a capacidade de troca catiônica (CTC). Para os solos de Campo Belo e Pouso Alegre não foram verificados grandes variações na sorção dos elementos estudados, em função de que esses solos apresentam uma maior quantidade da fração argila e matéria orgânica, quando comparados com o solo de Lavras e que, embora o solo de Pouso Alegre seja mais argiloso que o de Campo Belo, este último apresentou uma maior CTC em função do $\mathrm{pH}$ mais elevado e maior quantidade de matéria orgânica. Resultados que concordam com os obtidos por Araújo et al. (2002), Alleoni et al. (2005), Linhares et al. (2009 e 2010), Oliveira et al. (2010a e 2010b) e Costa (2013) que verificaram a adsorção máxima de metais pesados nos solos estudados, correlacionando positivamente com a CTC e com os teores de teores de argila, de silte, de óxidos de ferro e de alumínio, sendo ainda altamente dependente do $\mathrm{pH}$. 
(a)

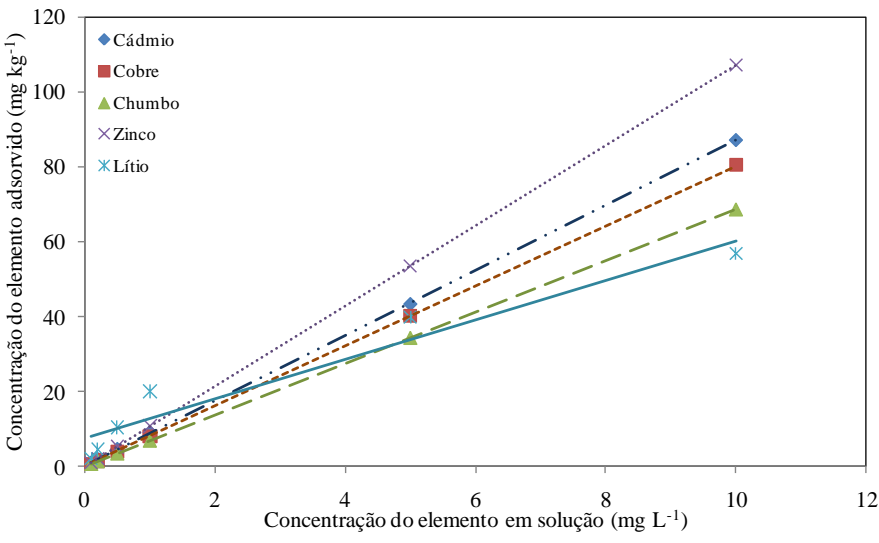

(b)

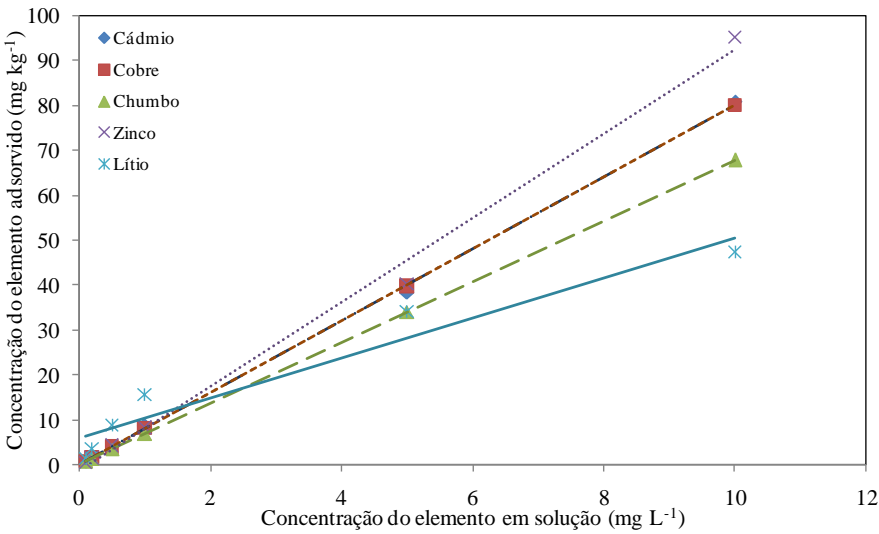

(c)

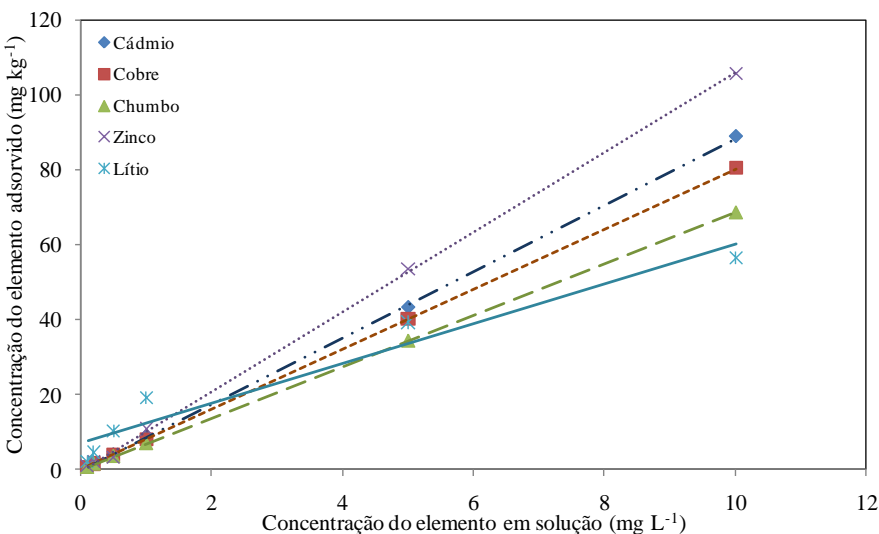

Figura 1. Isoterma de sorção os elementos $\mathrm{Cd}, \mathrm{Cu}, \mathrm{Li}$, $\mathrm{Pb}$ e $\mathrm{Zn}$ e os solos das áreas de disposição dos RSU dos municípios de (a) Campo Belo, (b) Lavras e (c) Pouso Alegre, MG.

Embora a diferença entre os modelos linear e potencial da isoterma tenha sido pequena, o modelo potencial permitiu verificar as diferenças na sorção dos elementos estudados no diferentes solos (Figura 1), principalmente para o Cd, Zn e Li. Com base no fator de partição de isoterma linear de sorção $(\mathrm{Kd})$, determinaram-se os valores dos fatores de retardamento $(\mathrm{R})$ cujos resultados permitiram inferir a respeito da sorção e da potencialidade de lixiviação dos elementos traços estudados (Tabela 2). O coeficiente Kd reflete a energia de ligação (Oliveira et al., 2013; Gonçalves et al., 2013) demonstrando que a maior parte dos sítios de adsorção 
possui alta afinidade pelos elementos traços avaliados, o que aumenta sua fixação no solo, reduz sua movimentação e disponibilização para o ambiente, que segundo Linhares et al. (2009) apresenta uma importância significativa em estudos ambientais.

Avaliando os valores obtidos para os coeficientes de partição e dos fatores de retardamento pode-se verificar a predominância pela sorção dos elementos bivalentes proporcionando uma redução na concentração desses elementos na solução do solo e da potencialidade da lixiviação e contaminação das águas subterrâneas em comparação com o Li que é monovalente (Tabela 2 e Figura 1). De um modo geral pode-se verificar que, para todos os solos estudados há uma tendência de preferência na sorção dos elementos traços avaliados, sendo o $\mathrm{Zn}$ com menor tendência a ser lixiviado, seguido do $\mathrm{Cd}, \mathrm{Cu}, \mathrm{Pb}$ e o $\mathrm{Li}$ com o maior potencial de contaminação das águas subterrâneas, por ser o elemento que apresentou a menor sorção nos solos estudados.

Com relação à contaminação do solo, verificou-se que para os maiores valores de concentração das soluções de $\mathrm{Cd}$ e $\mathrm{Cu}$, os valores adsorvidos ao solo foram superiores aos de referência preconizados na literatura. As concentrações máximas suportados nos solos de Campo Belo, Lavras e Pouso Alegre obtidas pelos modelos lineares das isotermas de sorção, para atender os valores de referência devem ser de 0,$15 ; 0,16$ e $0,15 \mathrm{mg} \mathrm{L}^{-1}$ para o Cd e de 7,48; 7,51 e 7,48 $\mathrm{mg} \mathrm{L}^{-1}$ para o $\mathrm{Cu}$, respectivamente. Com relação ao $\mathrm{Pb}$ e $\mathrm{Zn}$, os valores máximos adsorvidos foram inferiores ao de referência, não implicando em aportes excessivos desses elementos nos solos avaliados.

\section{CONCLUSÃO}

Para os elementos traços estudados o modelo de Freundlich empregado para descrever as isotermas de sorção apresentou um bom ajuste, permitindo, na faixa das concentrações estudadas, a sua utilização na previsão de retenção do $\mathrm{Cd}, \mathrm{Cu}, \mathrm{Li}, \mathrm{Pb}$ e $\mathrm{Zn}$ nos solos de áreas de disposição final de resíduos sólidos urbanos dos municípios em questão.

O solo de Campo Belo apresentou menor potencial à lixiviação dos elementos traços avaliados, sendo o solo de Lavras de maior vulnerabilidade à contaminação das águas subterrâneas, exigindo um maior controle na disposição de resíduos sólidos.

Com relação à mobilidade dos metais avaliados, verificou-se uma tendência de preferência na sorção dos elementos traços avaliados, sendo o $\mathrm{Zn}$ menos disponível para ser lixiviado e o Li com o maior potencial de contaminação das águas subterrâneas.

\section{AGRADECIMENTOS}

À Fundação de Amparo à Pesquisa do estado de Minas Gerais (FAPEMIG) pelo aporte financeiro para a realização deste trabalho.

\section{REFERÊNCIAS}

ABREU, L. B.; CARVALHO, G. S.; CURI, N.; GUILHERME, L. R. G.; MARQUES, J. J. G. S. M. Sorção de selênio em solos do bioma cerrado. Revista Brasileira de Ciência do Solo, v. 35, n. 6, p. 1995-2003, 2011. http://dx.doi.org/10.1590/S010006832011000600016

ALleONI, L. R. F.; IGLESIAS, C. S. M.; MELlO, S. C.; CAMARGO, O. A.; CASAGRANDE, J. C.; LAVORENTI, N. A. Atributos do solo relacionados à adsorção de cádmio e cobre em solos tropicais. Acta Scientiarum Agronomy, v. 27, n. 4, p. 729737, 2005. http://dx.doi.org/10.4025/actasciagron.v27i4.1348 
ANICETO, K. C. P.; HORBE, A. M. C. Solos urbanos formados pelo acúmulo de resíduos em Manaus, Amazonas, Brasil. Acta Amazônica, v. 42, n. 1, p. 135-148, 2012. http://dx.doi.org/10.1590/S0044-59672012000100016

ARANTES, S. A. C. M.; LIMA, J. M.; NÓBREGA, J. C. A.; GUILHERME L. R. G.; JULIÃO, L. G. F.; JESUS, E. A. Sorção de atrazina em solos representativos da subbacia do rio das Mortes - MG. Pesticidas: Revista de Ecotoxicologia e Meio Ambiente, Curitiba v. 16, p. 101-110, 2006.

ARAÚJO, W. S.; AMARAL SOBRINHO, N. M. B.; MAZUR, N.; GOMES, P. C. Relação entre adsorção de metais pesados e atributos químicos e físicos de classes de solo do Brasil. Revista Brasileira de Ciência do Solo, v. 26, n. 1, p. 17-27, 2002.

BIONDI, C. M.; NASCIMENTO, C. W. A.; FABRICIO NETA, A. B.; RIBEIRO, M. R. Teores de $\mathrm{Fe}, \mathrm{Mn}, \mathrm{Zn}, \mathrm{Cu}, \mathrm{Ni}$ e $\mathrm{Co}$ em solos de referência de Pernambuco. Revista Brasileira de Ciência do Solo, v. 35, n. 3, p. 1057-1066, 2011. http://dx.doi.org/10.1590/S0100-06832011000300039

BRASIL. Conselho Nacional do Meio Ambiente - CONAMA. Resolução n⿳0357, de 17 de março de 2005. Disponível em: <http://www.mma.gov.br/port/conama/res/res05/ res35705.pdf>. Acesso em: 06 mar. 2014.

BRASIL. Conselho Nacional do Meio Ambiente - CONAMA. Resolução n⿳0十220, de 28 de dezembro de 2009. Disponível em: <http://www.mma.gov.br/port/conama/ res/res09/res42009.pdf>. Acesso em: 06 mar. 2014.

CAIRES, S. M. Determinação dos teores naturais de metais pesados em solos do Estado de Minas Gerais como subsídio ao estabelecimento de Valores de Referência de Qualidade. 2009. 304f. Tese (Doutorado em Solos e Nutrição de Plantas) Universidade Federal de Viçosa, Viçosa, 2009.

CAMPOS, M. C. C. Atributos dos solos e riscos de lixiviação de metais pesados em solos tropicais. Ambiência, v. 6, n. 3, p. 547-565, 2010.

CAMPOS, M. L.; PIERANGELI, M. A. P.; GUILHERME, L. R. G.; MARQUES, J. J. G. S. M.; CURI, N. Baseline concentration of heavy metals in Brazilian Latosols. Communications in Soil Science and Plant Analysis, v. 34, p. 547-557, 2003. http://dx.doi.org/10.1081/CSS-120017838

CARVALHO, S. R.; VILAS BÔAS, G. S.; FADIGAS, F. S. Concentrações naturais de metais pesados em solos derivados de sedimentos do grupo Barreiras. Cadernos de Geociências, v. 10, n. 2, p. 97-107, 2013.

CASARINI, D. C. P.; DIAS, C. L.; LEMOS, M. M. G. Critérios de qualidade de solos e águas subterrâneas no estado de São Paulo - valores orientadores. In: CONGRESSO BRASILEIRO DE ÁGUAS SUBTERRÂNEAS, 12., 2002. Disponível em: <http://aguassubterraneas.abas.org/asubterraneas/article/view/22331/14674>. Acesso em: 06 mar. 2014.

CELERE, M. S.; OLIVEIRA, A. S.; TREVILATO, T. M. B.; SEGURA-MUNHÕZ, S. I. Metais presentes no chorume coletado no aterro sanitário de Ribeirão Preto, São Paulo, Brasil e sua relevância para saúde pública. Cadernos de Saúde Pública, v. 23, n. 4, p. 939-947, 2007. http://dx.doi.org/10.1590/S0102-311X2007000400021 
CHAVES, L. H. G.; TIT, G. A. Cadmium and copper adsorption on bentonite: effects of pH and particle size. Revista Ciência Agronômica, v. 42, n. 2, p. 278-284, 2011. http://dx.doi.org/10.1590/S1806-66902011000200004

CHAVES, L. H. G.; SOUZA, R. S.; TIT, G. A. Adsorção de zinco em argissolos do estado da Paraíba: efeito do pH. Revista Ciência Agronômica, v. 39, n. 4, p. 511-516, 2008.

CIOTTA, M. N.; BAYER, C.; FONTOURA, S. M. V.; ERNANI, P. R.; ALBUQUERQUE, J. A. Matéria orgânica e aumento da capacidade de troca de cátions em solo com argila de atividade baixa sob plantio direto. Ciência Rural, v. 33, n. 6, p.1161-1164, 2003. http://dx.doi.org/10.1590/S0103-84782003000600026

COMPANHIA AMBIENTAL DO ESTADO DE SÃO PAULO - CETESB. Manual de gerenciamento de áreas contaminadas. 2001. Disponível em: <http://www.cetesb.sp.gov.br/areas-contaminadas/manual-de-gerenciamento-de-areascontaminadas/7-manual-de-gerenciamento-das--acs>. Acesso em: 9 fev. 2013.

CORRÊA, R. M.; NASCIMENTO, C. W. A.; ROCHA, A. T. Adsorção de fósforo em dez solos do Estado de Pernambuco e suas relações com parâmetros físicos e químicos. Acta Scientiarum Agronomy, v. 33, n. 1, p. 153-159, 2011. http://dx.doi.org/10.4025/actasciagron.v33i1.3129

CORREIA, F. V.; LANGENBACH, T.; CAMPOS, T. M. Avaliação do transporte de atrazina em solos sob diferentes condições de manejo agrícola. Revista Brasileira de Ciência do Solo, v. 34, n. 2, 2010. http://dx.doi.org/10.1590/S0100-06832010000200026

COSTA, W. P. L. B. Metais pesados em solos do Rio Grande do Norte: valores de referência de qualidade e relações geopedológicas. 2013. 121f. Tese (Doutorado em Ciência do Solo) - Universidade Federal Rural de Pernambuco, Recife, 2013.

EMPRESA BRASILEIRA DE PESQUISA AGROPECUÁRIA - EMBRAPA. Centro Nacional de Pesquisa de Solos. Manual de métodos de análise de solos. $2^{\mathrm{a}} \mathrm{ed}$. Rio de Janeiro, 1997. 212p.

FADIGAS, F. S.; AMARAL SOBRINHO, N. M. B.; MAZUR, N.; ANJOS, L. H. C.; FREIXO, A. A. Concentrações naturais de metais pesados de metais pesados em algumas classes de solos Brasileiros. Bragantia, v. 61, n. 2, p. 151-159, 2002.

http://dx.doi.org/10.1590/S0006-87052002000200008

FADIGAS, F. S.; AMARAL SOBRINHO, N. M. B.; MAZUR, N.; ANJOS, L. H. C.; FREIXO, A. A. Proposição de valores de referência para a concentração natural de metais pesados em solos brasileiros. Revista Brasileira de Engenharia Agrícola e Ambiental, v. 10, n. 3, p. 699-705, 2006a. http://dx.doi.org/10.1590/S141543662006000300024

FADIGAS, F. S.; AMARAL SOBRINHO, N. M. B.; MAZUR, N.; ANJOS, L. H. C. Estimation of reference values for $\mathrm{Cd}, \mathrm{Co}, \mathrm{Cr}, \mathrm{Cu}, \mathrm{Ni}, \mathrm{Pb}$ and $\mathrm{Zn}$ in Brazilian soil. Communications in Soil Science and Plant Analysis, v. 37, p. 945-959, 2006b. http://dx.doi.org/10.1080/00103620600583885

FRANCO, C. S. Caracterização gravimétrica dos resíduos sólidos domiciliares e percepção dos hábitos de descarte no sul de Minas. 2012. 157f. Dissertação (Mestrado em Recursos Hídricos em Sistemas Agrícolas) - Universidade Federal de Lavras, Lavras, 2012. 
FREEZE, A.; CHERRY, J. A. Groundwater. New Jersey: Prentice-Hall; Englewood Cliffs, 1979. 604p.

GONÇALVES, M. S.; BETTIN, J. P.; SILVA JUNIOR, L. C. S.; SAMPAIO, S. C.; DAL BOSCO, T. C. Adequação dos modelos de Langmuir e Freundlich na adsorção de cobre em solo argiloso do sul do Brasil. Holos, v. 4, n. 29, p. 37-44, 2013.

GOUVEIA, N.; PRADO, R. R. Riscos à saúde em áreas próximas a aterros de resíduos sólidos urbanos. Revista de Saúde Pública, v. 44, n. 5, p. 859-66, 2010. http://dx.doi.org/10.1590/S0034-89102010005000029

GUILHERME, L. R. G.; MARQUES, J. J.; PIERANGELI, M. A. P.; ZULIANI, D. Q.; CAMPOS, M. L.; MARCHI, G. Elementos-traço em solos e sistemas aquáticos. In: TORRADO-VIDAL, P.; ALlEONI, L. R. F.; COOPER, M.; SILVA, A. P. (Eds.). Tópicos em ciência do solo. Viçosa, MG: Sociedade Brasileira de Ciência do Solo, 2005. Vol 4. p. 345-390.

INSTITUTO BRASILEIRO DE GEOGRAFIA E ESTATÍSTICA - IBGE. Cidades@. Disponível em: <http://www.ibge.gov.br/cidadesat>. Acesso em: 9 jan. 2013.

KEMERICH, P. D. C.; MENDES, S. A.; VORPAGEL, T. H.; PIOVESAN, M. Impactos ambientais decorrentes da disposição inadequada de lixo eletrônico no solo. Engenharia Ambiental, v. 10, n. 2, p. 208-219, 2013.

LANGE, L. C.; SIMÕES, G. F.; FERREIRA, C. F. A.; COELHO, H. M. G. Estudo do transporte de contaminantes em meios porosos Aplicado a aterros de disposição de resíduos sólidos urbanos. In: CASTILHOS JUNIOR, A. B.; LANGE, L. C.; GOMES, L. P.; PESSIN, N. Alternativas de disposição de resíduos sólidos urbanos para pequenas comunidades. Rio de Janeiro: RiMa; ABES, 2002. p-85-92.

LINHARES, L. A.; EGREJA FILHO, F. B.; OLIVEIRA, C. V.; BELLIS, V. M. Adsorção de cádmio e chumbo em solos tropicais altamente intemperizados. Pesquisa

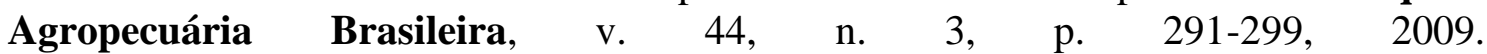
http://dx.doi.org/10.1590/S0100-204X2009000300011

LINHARES, L. A.; EGREJA FILHO, F. B.; BELLIS, V. M.; SANTOS, E. A.; IANHEZ, R. Utilização dos modelos de Langmuir e de Freundlich na adsorção de cobre e zinco em solos Brasileiros. Acta Agronómica, v. 59, n. 3, p. 303-315, 2010.

MACHADO, M. E.; MENEZES, J. C. S. S.; COSTA, J. F. C. L.; SCHNEIDER, I. A. H. Análise e avaliação da distribuição de metais pesados em um antigo aterro de resíduos sólidos urbanos "Aterro Invernadinha”. Evidência, v. 11, n. 2, p. 69-82, 2011.

MARTINS, C. A. S.; NOGUEIRA, N. O.; RIBEIRO, P. H.; RIGO, M. M.; CANDIDO, A. O. A dinâmica de metais-traço no solo. Revista Brasileira de Agrociência, v. 17, n. 3/4, p. 383-391, 2011.

NICOCHELlI, L. M.; NASCENTES, R.; LIMA, E. B. N. R.; SOARES, F. S. C. Sorção de potássio em amostras de solo submetidas à aplicação de vinhaça. Revista Brasileira de Engenharia Agrícola e Ambiental, v. 16, n. 7, p. 754-760, 2012. http://dx.doi.org/10.1590/S1415-43662012000700008 
OLIVEIRA, F. C.; MATTIAZZO, M. E. Mobilidade de metais pesados em um latossolo amarelo distrófico tratado com lodo de esgoto e cultivado com cana-de-açúcar. Scientia Agrícola, v. 58, n. 4, p. 807-812, 2001. http://dx.doi.org/10.1590/S010390162001000400024

OLIVEIRA, F. J. S.; JUCÁ, J. F. T. Acúmulo de metais pesados e capacidade de impermeabilização do solo imediatamente abaixo de uma célula de um aterro de resíduos sólidos. Engenharia Sanitária e Ambiental, v. 9, n. 3, p. 211-217, 2004. http://dx.doi.org/10.1590/S1413-41522004000300007

OLIVEIRA, L. F. C.; LEMKE DE CASTRO, M. L.; RODRIGUES, C.; BORGES, J. D. Adsorção e deslocamento do íon cádmio em solos do cerrado. Revista Brasileira de Engenharia Agrícola e Ambiental, v. 14, n. 8, p. 848-855, 2010a. http://dx.doi.org/10.1590/S1415-43662010000800009

OLIVEIRA, L. F. C.; LEMKE DE CASTRO, M. L.; RODRIGUES, C.; BORGES, J. D. Isotermas de sorção de metais pesados em solos do cerrado de Goiás. Revista Brasileira de Engenharia Agrícola e Ambiental, v. 14, n. 7, p. 776-782, 2010b. http://dx.doi.org/10.1590/S1415-43662010000700014

OLIVEIRA, L. F. C.; NOGUEIRA, J. G.; FRIZZARIM, S. S.; FIA, R.; FREITAS, J. S.; FIA, F. R. L. Sorção e mobilidade do lítio em solos de áreas de disposição final de resíduos sólidos urbanos. Engenharia Sanitária e Ambiental, v. 18, n. 2, p. 139-148, 2013. http://dx.doi.org/10.1590/S1413-41522013000200006

OLIVEIRA, S.; PASQUAL, A. Avaliação de parâmetros indicadores de poluição por efluente líquido de aterro sanitário. Engenharia Sanitária e Ambiental, v. 9, n. 3, p. 240-249, 2004. http://dx.doi.org/10.1590/S1413-41522004000300010

OLIVEIRA, T. S.; COSTA, L. M.; CRUZ, C. D. Importância relativa dos metais pesados do solo na identificação e separação de materiais de origem. Revista Ceres, v. 45, n. 260, p. 359-371, 1998.

PAYE, H. S.; MELLO, J. W. V.; ABRAHÃO, W. A. P.; FERNANDES FILHO, E. I.; DIAS, L. C. P.; CASTRO, M. L. O. et al. Valores de referência de qualidade para metais pesados em solos no Estado do Espírito Santo. Revista Brasileira de Ciência do Solo, v. 34, n. 6, p. 2041-2051, 2010. http://dx.doi.org/10.1590/S0100-06832010000600028

PIAZ, J. F. D.; FERREIRA, G. M. V. Gestão de resíduos sólidos domiciliares urbanos: o caso do município de Maraú, RS. Revista de Gestão Social e Ambiental, v. 5, n. 1, p. 33 47, 2011. http://dx.doi.org/10.5773/rgsa.v5i1.248

PIERANGELI, M. A. P.; GUILHERME, L. R. G.; CURI, N.; COSTA, E. T. S.; LIMA, J. M.; MARQUES, J. J. G. S. M. et al. Comportamento sortivo, individual e competitivo, de metais pesados em Latossolos com mineralogia contrastante. Revista Brasileira de Ciência do Solo, v. 31, n. 4, p. 819-826, 2007. http://dx.doi.org/10.1590/S010006832007000400022

PIERANGELI, M. A. P.; EGUCHI, E. S.; RUPPIN, R. F.; VIEIRA, F. V.; COSTA, R. B. F. Teores de $\mathrm{As}, \mathrm{Pb}, \mathrm{Cd}$ e $\mathrm{Hg}$ e fertilidade de solos da região do Vale do Alto Guaporé, sudoeste do estado de Mato Grosso. Acta Amazonica, v. 39, n. 1, p. 59-67, 2009. http://dx.doi.org/10.1590/S0044-59672009000100006 
PRATA, F.; LAVORENTI, A.; REGITANO, J. B.; TORNISIELO, V. L. Influência da matéria orgânica na sorção e dessorção do glifosato em solos com diferentes atributos mineralógicos. Revista Brasileira de Ciência do Solo, v. 24, p. 947-951, 2000.

SOUZA, R. S.; CHAVES, L. H. G.; FERNANDES, J. D. Adsorção de zinco e sua relação com características de solos do Estado da Paraíba. Revista Brasileira de Ciências Agrárias, v.1, n. único, p. 1/6, 2006.

TAGliaferRO, G. V.; PEREIRA, P. H. F.; RODRIGUES, L. A.; SilVA, M. L. C. P. Adsorção de chumbo, cádmio e prata em óxido de nióbio hidratado preparado pelo método da precipitação em solução homogênea. Química Nova, v. 34, n. 1, p. 101-105, 2011. http://dx.doi.org/10.1590/S0100-40422011000100020 